\title{
Coordinated Placement and Setting of FACTS in Electrical Network based on Kalai-smorodinsky Bargaining Solution and Voltage Deviation Index
}

\author{
Aziz Oukennou ${ }^{1}$, Abdelhalim Sandali' ${ }^{2}$, Samira Elmoumen ${ }^{3}$ \\ ${ }^{1,2}$ Advanced Control of Electrical Systems Team-LESE, ENSEM, Hassan II University, Morocco \\ ${ }^{3}$ LIMSAD, Mathematics and Computing Department, Ain Chock Sciences Faculty, Morocco
}

\begin{tabular}{l} 
Article Info \\
\hline Article history: \\
Received Apr 30, 2018 \\
Revised Jul 11, 2018 \\
Accepted Aug 2, 2018 \\
\hline
\end{tabular}

Keyword:

Differential evolution

FACTS

Kalai Smorodinsky bargaining solution

Multiobjective optimization

Optimal power flow

Pareto front

SVC

TCSC

Voltage stability index

\begin{abstract}
To aid the decision maker, the optimal placement of FACTS in the electrical network is performed through very specific criteria. In this paper, a useful approach is followed; it is based particularly on the use of KalaiSmorodinsky bargaining solution for choosing the best compromise between the different objectives commonly posed to the network manager such as the cost of production, total transmission losses (Tloss), and voltage stability index (Lindex). In the case of many possible solutions, Voltage Profile Quality is added to select the best one. This approach has offered a balanced solution and has proven its effectiveness in finding the best placement and setting of two types of FACTS namely Static Var Compensator (SVC) and Thyristor Controlled Series Compensator (TCSC) in the power system. The test case under investigation is IEEE-14 bus system which has been simulated in MATLAB Environment.
\end{abstract}

Corresponding Author:

Aziz Oukennou,

Department of Industrial Engineering,

National School of Applied Sciences, 63, Safi, Morocco.

Email: a.oukennou@uca.ma

\section{INTRODUCTION}

With the growth of the demand and many voltage collapse incidents recorded recently around the world [1], The installation of Flexible AC Transmission Systems (FACTS) in the network is required. Based on power electronics, these new devices offer an opportunity to enhance controllability, stability, and transfer capability of the interconnected power systems [2], [3]. The investment cost of FACTS is still very expensive, but focusing on their importance, TCSC has the primary function to increase power transfers significantly and enhance stability. On the other hand, SVC is qualified as the preferred FACTS to provide reactive power at key points of the power system. It also presents the lowest price as it has no moving or rotating main components and presents cheap maintenance costs [4], [5]. Given the high price of FACTS, numerous studies have attempted to identify the best placement and size of these equipments in order to take advantage of their contribution in an optimal way with less investment.

Various techniques depending on the technical or economical target fixed by the operator were used and were very useful. It started from fixing single-objective such as stability improvement [6], loss minimization [7], power quality improvement [8] ...etc. In this case, the decision is made quickly but has the disadvantage of the improvement of the chosen criterion to the detriment of the other performances. 
Conversely, in the case of multiple objectives which are very frequent [9]-[11], the processing becomes more complex. Some methods consist of summing all the objectives by assigning a weight coefficient that the decision-maker has to attribute to each one [12], [13]. The order of magnitude must also be known in advance. Moreover, the result of the optimization is not unique but there are other possible solutions that can be presented as Pareto Front (PF) [14], [15].

The computing of this set of solutions takes enough time as it requires a large number of monoobjective functions optimization. It is also difficult to qualify concretely one of these solutions as the best one. In this contest, other methods have been used to select the best compromise. We quote for example NSGA II [16],[17] and NPSO [18] which are more popular and considered as one of the best methods used to solve the problem of FACTS optimal placement. For these methods, the degree of complexity seems to be increasingly important given the time required for running and the need to trace the Pareto Front to finally select the most dominant solution called the best compromise.

The Kalai-Smorodinsky (KS), suggested by Ehud Kalai and Meir Smorodinsky [19], [20], is a solution to the Bargaining problem where players make decisions in order to optimize their own utility. In engineering problems, players are replaced by the objective functions that the operators have to optimize at the same time. The main advantage of KS solution is that it provides a concrete criterion to select only and only one unique point along the Pareto Front.

The objective of this work is to apply the Kalai-Smorodinsky technique in the optimal placement and setting of coordinated FACTS in power systems by considering three objectives namely Cost function, Total Transmission losses and Lindex as players. In the case of multiple KS Solutions, Voltage Deviation Index is added as new criteria to improve Voltage Profile Quality. The proposed method helps to choose only one unique solution without exploring the whole Pareto Front which saves computational time considerably.

The rest of the paper is organized as follows. Section 2 presents a review of the optimal power flow problem. Optimization tool is described in section 3. Case study, the model of SVC, TCSC, and objectives functions are presented in Sections 4. The results of simulation and discussion are presented in section 5. The conclusion is the subject of section 6 .

\section{OPTIMAL POWER FLOW PROBLEM}

The optimal power flow (OPF) problem is the backbone tool for power system operation. The aim of the OPF problem is to determine the optimal operating state of a power system by optimizing a particular objective in power systems while satisfying certain operating constraints [21]. Mathematically, the OPF problem can be formulated as follow:

$$
\min F_{o b j}(x, u)
$$

Subject to

$$
\begin{aligned}
& \mathrm{g}(x, u)=0 \\
& \mathrm{~h}(x, u) \leq 0
\end{aligned}
$$

$\mathrm{F}_{\mathrm{obj}}$ can take various functions depending on the target fixed by the operator. In the OPF, the equalities and inequalities are as follows:

a. Equality constraints:

$$
\begin{aligned}
& P_{i}(V, \delta)-P_{G i}+P_{D i}=0 \\
& Q_{i}(V, \delta)-Q_{G i}+Q_{D i}=0
\end{aligned}
$$

And load balance equation:

$$
\sum_{i=1}^{N_{G}} P_{G i}=\sum_{i=1}^{N_{D i}} P_{D i}+P_{L}
$$

b. Inequality constraints:

The inequality constraints represent the limits on all variables such as the generator voltage, active and reactive powers. 


$$
\begin{aligned}
& V_{\text {Gimin }} \leq V_{G i} \leq V_{\text {Gimax }} \quad \mathrm{i}=1, \ldots, N_{G} \\
& P_{\text {Gimin }} \leq P_{G i} \leq P_{\text {Gimax }} \mathrm{i}=1, \ldots, N_{G} \\
& Q_{\text {Gimin }} \leq Q_{G i} \leq Q_{\text {Gimax }} \quad \mathrm{i}=1, \ldots, N_{G}
\end{aligned}
$$

The maximum and minimum limits of tap settings regarding the transformer and which takes discrete values is given by,

$$
T_{k \min } \leq T_{k} \leq T_{k \max } \quad k=1, \ldots, N_{T}
$$

\section{KALAI-SMORODINSKY SOLUTION AND DIFFERENTIAL EVOLUTION}

\subsection{Kalai-Smorodinsky bargaining Solution}

In the multi-objective optimization problem, when many objective functions are conflicting, there are many possible solutions. It is impossible to make any preference criterion better off without making at least one preference criterion worst off. The advantage of KS Solution is that it satisfies monotonicity so each objective can be improved weakly better. Mathematically, it is the intersection point of the segment Ut (point of best utilities) and the point of disagreement $\mathrm{D}$ with the edge of the feasible set (Pareto Front) as shown in Figure 1. To be near from Ut, goal programming optimization technique will be deployed to achieve this target in equation 11 .

$$
F K S=\alpha\left(f_{1}-U_{t 1}\right)^{2 n}+\beta\left(f_{2}-U_{t 2}\right)^{2 p}
$$

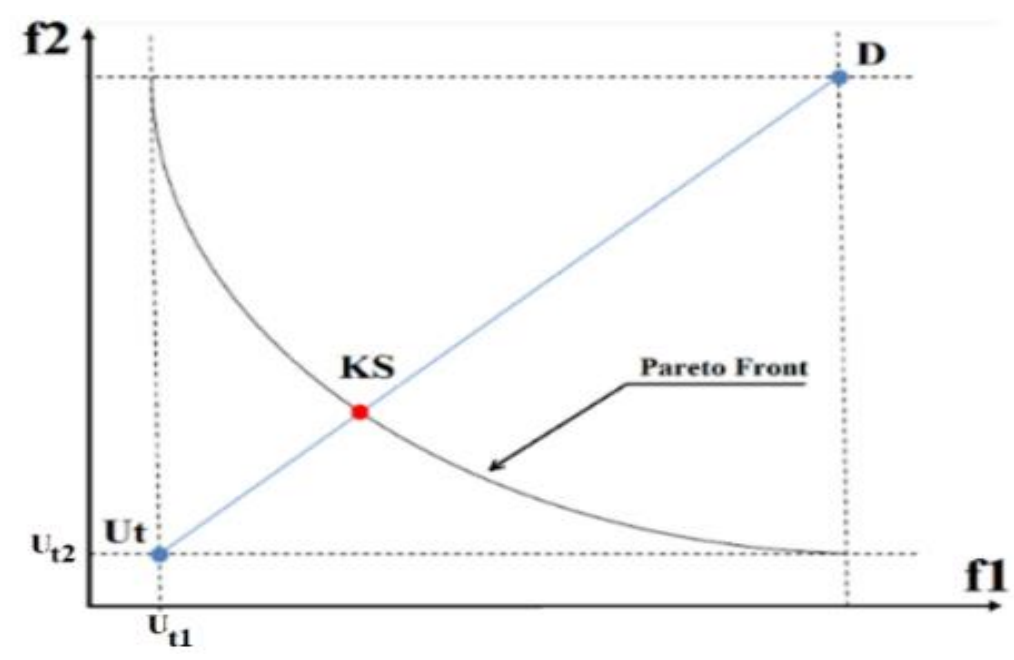

Figure 1. Solution of Kalai Smorodinsky (KS) between two functions f1 and f2

\subsection{Differential Evolution Algorithm}

Differential Evolution (DE) [22] is one of the most powerful algorithms for real number function optimization problems. The potential of this technique was demonstrated in literature and was compared to other techniques such as Genetic Algorithm (GA) and Particle Swarm Optimization (PSO) especially to resolve the OPF problem [23] and proved superiority in terms of solution quality. The flowchart of this algorithm is shown in Figure 2. 


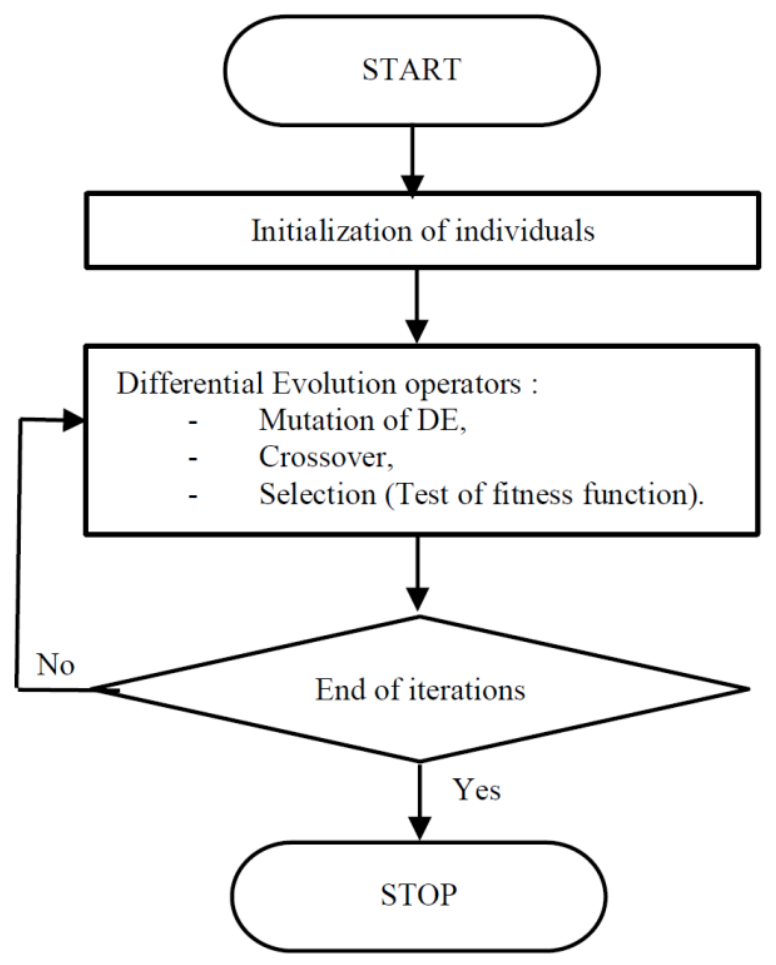

Figure 2. Flowchart of DE algorithm

\section{CASE STUDY, MODELING OF FACTS, AND OBJECTIVE FUNCTIONS}

\subsection{Case Study}

Our study is done on the standard IEEE 14-bus test system shown in Figure 3. It represents a simple approximation of the American Electric Power system; it has 14 buses, 20 interconnected branches, 5 generators and 9 load busbars.

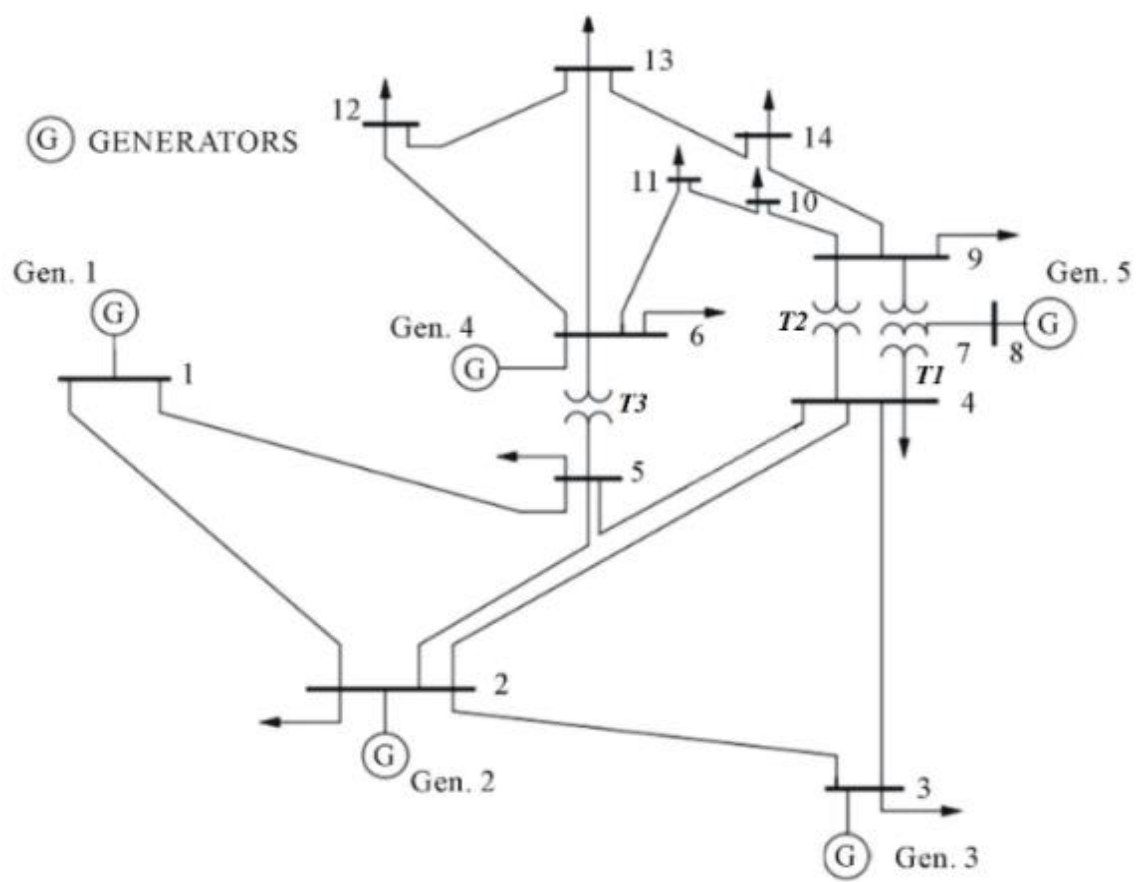

Figure 3. One-line diagram of IEEE 14-bus Test system taken from [24] 


\subsection{Model of SVC and TCSC}

\subsubsection{SVC}

The Static Var Compensator (SVC) equipment is composed of capacitors, thyristors, and inductances. In this paper, it is considered as an ideal reactive power controller, which injects or absorbs reactive power in the network. The bus where the SVC is placed is considered as a PV bus where the voltage is controlled and equal to the unity. A negative value indicates that the SVC generates reactive power and injects it into the network (capacitive state) and a positive value indicates that the SVC absorbs reactive power from the network (inductive state).

\subsubsection{TCSC}

The TCSC is a series compensation device that can modify and adjust the transmission line reactance as shown in Figure 4. By this way, the power transfer ability is improved in steady-state. The new value of reactance of the line where TCSC is installed is given by:

$$
X_{i j}=(1+k) X
$$

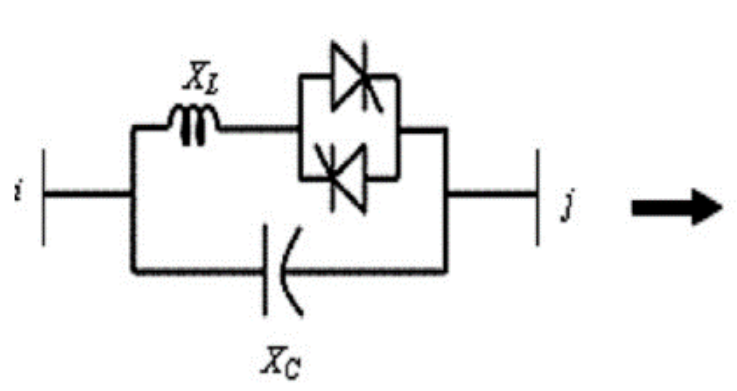

(a)

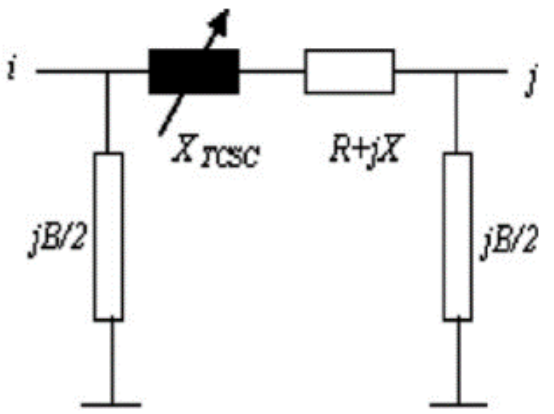

(b)

Figure 4. The basic structure of TCSC (a) and model (b)

The range of compensation $(\mathrm{k} \%)$ of the TCSC is taken between $20 \%$ inductive and $80 \%$ capacitive $(-0.8 \leq \mathrm{k} \leq 0.2)[25]$.

\subsection{Objective functions}

Three objective functions will be considered The first investigated one is the generation fuel cost minimization; it is expressed as:

$$
F_{\text {cost }}=\sum_{i=1}^{N_{G}}\left(\alpha_{i} P_{G i}^{2}+\beta_{i} P_{G i}+\gamma_{i}\right) \quad(\$ / \mathrm{h})
$$

$\alpha_{i}, \beta_{i}$ and $\gamma_{i}$ are the cost coefficients of the ith generator. The technical objective function is the Total Power losses and is given by:

$$
\text { Tloss }=\sqrt{P_{l}^{2}+Q_{l}^{2}} \quad(\mathrm{MVA})
$$

where $\mathrm{Pl}$ and $\mathrm{Ql}$ are the active and reactive power losses of the power system. The last objective function related to security is the voltage stability index (Lindex) [26],[27]. It is given by:

$$
\text { Lindex }=\max \left\{L_{j}\right\}=\max _{1 \leq j \leq N_{L}}\left|1-\frac{\sum_{i=1}^{N_{G}} \underline{F_{j i}} \underline{V_{i}}}{\underline{V_{j}}}\right|
$$

$V_{i}$ and $V_{j}$ are the complex voltage of ith and jth generators, $N_{G}$ is the number of generator units and $N_{L}$ is the number of load bus. L-index varies in a range between 0 (no Load) and 1 (voltage collapse). 


\section{SIMULATION AND RESULTS}

In order to identify the best coordinated placement of SVC and TCSC device. Figure 5 is respected for each pair of objective functions selected. Since FACTS have an interval where they can operate, all buses and lines will be scanned to have the best location and the value of Kalai Smorodinsky's solution.

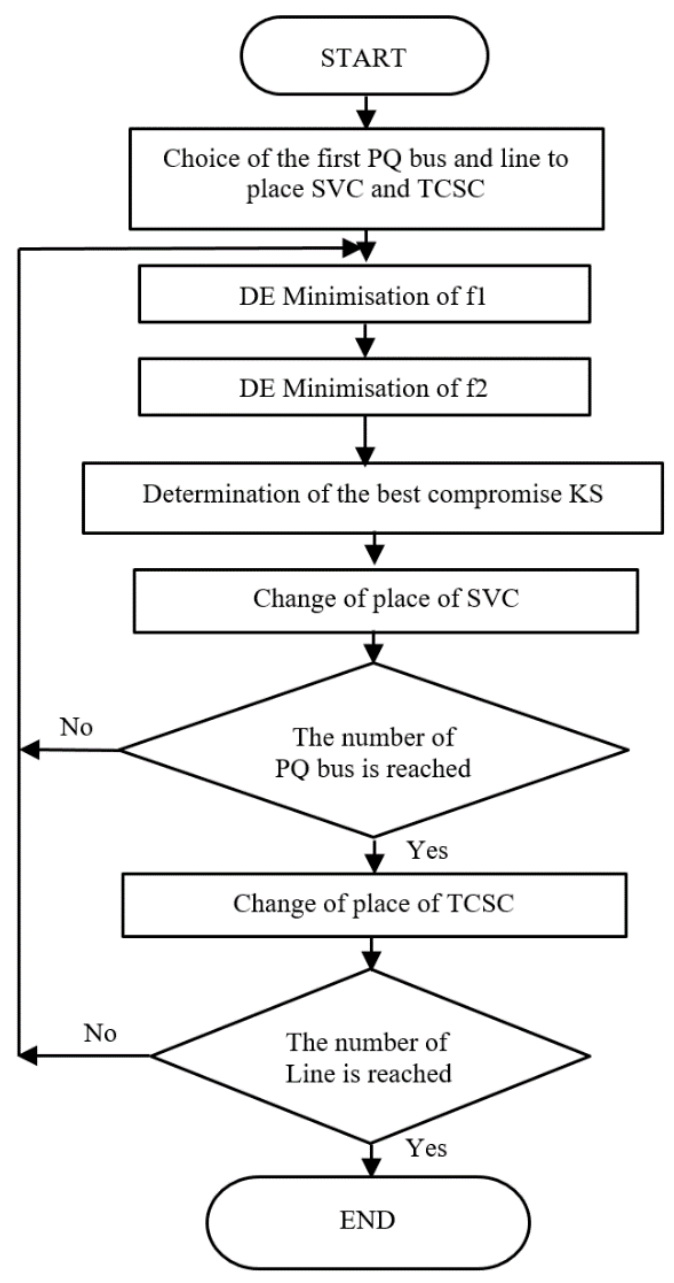

Figure 5. Flowchart of algorithm for placement

In the case of many KS solutions, the voltage profile quality in equation 16 will be considered as additional criteria to select the best one. The index is given by:

$$
V D=\sum_{i=1}^{N}\left|V_{i}-1\right|
$$

where $\mathrm{N}$ is the total number of buses in the system.

In all that follows, the reactive power of the generators is considered unrestricted and on the other side, the voltages of generators are taken constant which is possible because the real systems possess means for regulating the voltage automatically (AVR). The only control variables that will be considered are: Active power of generators and tap changers. However, the necessary values of reactive power of SVC, and range of compensation of TCSC $(\mathrm{k} \%)$ will be computed.

\subsection{Tloss and Cost Function}

The obtained results are as can see in Figure 6. Five non-dominated locations are identified for SVC and TCSC placement. The solution number (5) is excluded as it considers the bus 7 for SVC placement, or it is a part of the three-winding-transformer. Using the voltage deviation index (VD), the solution (1) is the best one where it is equal to $0.59 \mathrm{pu}$, then SVC is placed in Bus 14 and TCSC in line 1-5. To evaluate the result of 
this simulation, two others DE mono-objective optimizations were done to find the best Cost and the best Total Losses minimization without FACTS. Table 1 gives the obtained results in comparison with KS Solution with FACTS.

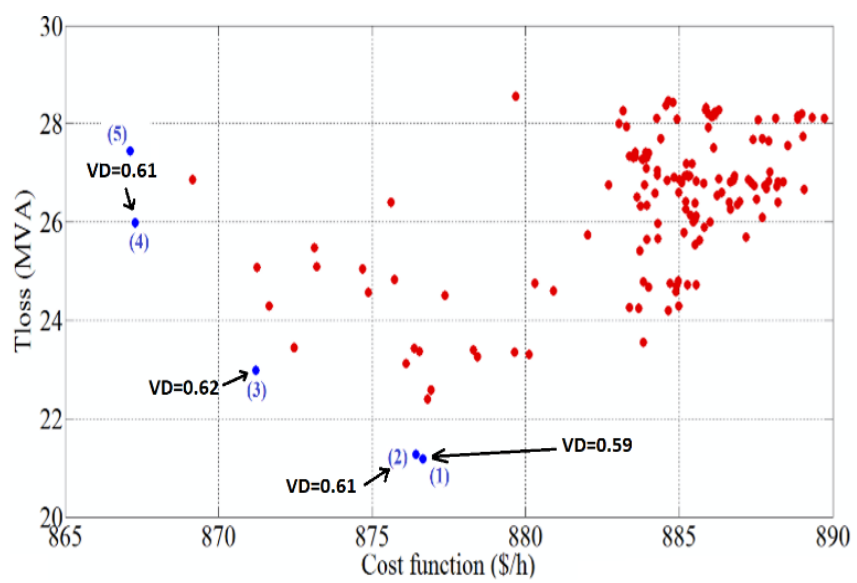

Figure 6. KS Solutions in case 5.1

Table 1. Control variables and objective functions in case 5.1

\begin{tabular}{|c|c|c|c|c|c|c|c|c|c|c|c|c|c|c|c|c|}
\hline & & \multicolumn{2}{|c|}{ SVC } & \multicolumn{2}{|c|}{ TCSC } & \multicolumn{8}{|c|}{ Optimal values of control variables } & \multirow[b]{2}{*}{$\begin{array}{l}\text { Cosh } \\
(\$ / h)\end{array}$} & \multirow{2}{*}{$\begin{array}{c}\text { Total } \\
\text { Losses } \\
\text { (MVA) }\end{array}$} & \multirow[b]{2}{*}{$\begin{array}{l}\text { VD } \\
(\mathrm{pu})\end{array}$} \\
\hline & & $\begin{array}{l}\text { Best } \\
\text { loc. }\end{array}$ & $\begin{array}{c}\text { Best } \\
\text { set. }\end{array}$ & $\begin{array}{l}\text { Best } \\
\text { loc. }\end{array}$ & $\begin{array}{c}\text { Best } \\
\text { set. }\end{array}$ & $\begin{array}{l}\mathrm{Pg} 1 \\
(\mathrm{pu})\end{array}$ & $\begin{array}{l}\mathrm{Pg} 2 \\
(\mathrm{pu})\end{array}$ & $\begin{array}{l}\mathrm{Pg} 3 \\
(\mathrm{pu}) \\
\end{array}$ & $\begin{array}{l}\text { Pg6 } \\
(\mathrm{pu})\end{array}$ & $\begin{array}{l}\mathrm{Pg} 8 \\
(\mathrm{pu})\end{array}$ & $\mathrm{T} 1$ & $\mathrm{~T} 2$ & $\mathrm{~T} 3$ & & & \\
\hline \multirow{2}{*}{ 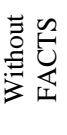 } & Best cost & - & - & - & - & 2.13 & 0.20 & 0.15 & 0.10 & 0.10 & 1.01 & 0.90 & 0.99 & 826.58 & 48.03 & 0.71 \\
\hline & $\begin{array}{l}\text { Best } \\
\text { losses }\end{array}$ & - & - & - & - & 0.97 & 0.80 & 0.50 & 0.35 & 0.10 & 1.10 & 0.98 & 1.03 & 983.12 & 20.45 & 0.70 \\
\hline 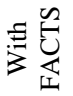 & $\begin{array}{l}\text { Best KS } \\
\text { Solution }\end{array}$ & $\begin{array}{c}\text { Bus } \\
14\end{array}$ & -0.13 & $\begin{array}{c}\text { Line } \\
1-5\end{array}$ & -0.80 & 1.50 & 0.34 & 0.28 & 0.35 & 0.17 & 1.00 & 0.99 & 0.99 & 876.64 & 21.18 & 0.59 \\
\hline
\end{tabular}

Without FACTS, the values of objectives functions are better. However, the values of the other performances are worst, For Cost Minimization, the value of Total losses is equal to 48.03MVA, and the value of Cost production is equal to $876.64 \$ / \mathrm{h}$ in Total Losses minimization. The two values are much improved with KS solution which gives a very good compromise. In addition to this, the voltage deviation is reduced in the proposed approach.

\subsection{Lindex and Cost Function}

The summarized results of the simulation are given in Figure 7. Four dominated KS solutions are obtained, the solutions (3) and (4) are related to bus 7 which represents in reality, the three windingtransformer so they are excluded. In this case only solution (1) and (2) are maintained. Focusing on Voltage Deviation Index of each solution, the second one is better. SVC is installed in bus 9 and TCSC in line 4-9. Both of these equipments operate in capacitive state. Table 2 gives a comparison study between the optimization results of the proposed solution and the traditional mono-objectif optimization of cost function or Lindex.

As seen in Table 2, the mono-objective optimization of Cost function has allowed to have the best optimal cost $(826.59 \$ / \mathrm{h})$ which means an economic gain. However, the degree of stability is reduced since the Lindex is high. The same logic can be applied for Lindex optimization where stability is improved at the detriment of production cost. In the case of our approach and using FACTS, all objective functions are in the acceptable range. We also note that Lindex and voltage deviation are better which means more security and best voltage profile in the whole power system. 


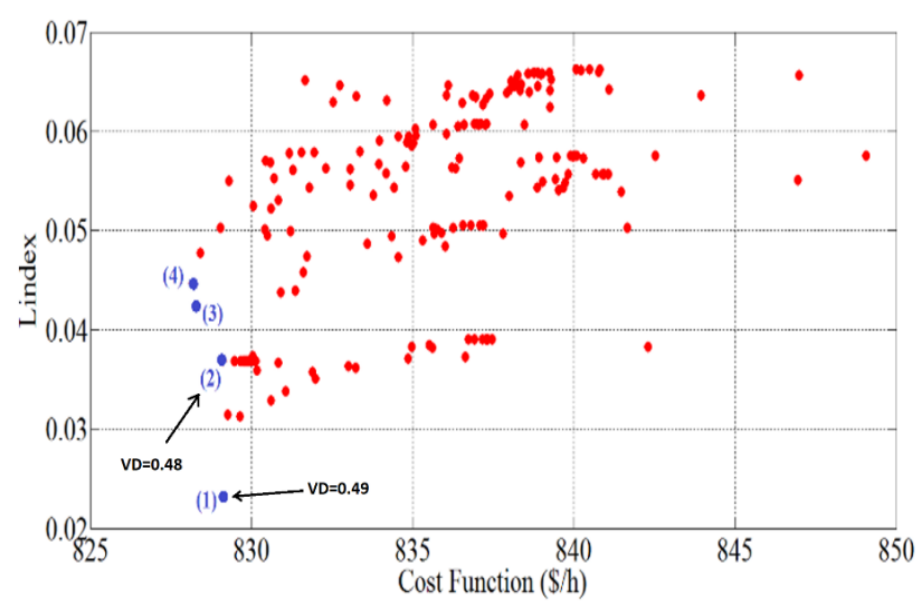

Figure 7. KS Solutions in case 5.2

Table 2. Control Variables and Objective Functions in Case 5.2

\begin{tabular}{|c|c|c|c|c|c|c|c|c|c|c|c|c|c|c|c|c|}
\hline & & \multicolumn{2}{|c|}{ SVC } & \multicolumn{2}{|c|}{ TCSC } & \multicolumn{8}{|c|}{ Optimal values of control variables } & \multirow{2}{*}{$\begin{array}{l}\text { Cosh } \\
(\$ / h)\end{array}$} & \multirow[b]{2}{*}{ Lindex } & \multirow{2}{*}{$\begin{array}{l}\text { VD } \\
\text { (pu) }\end{array}$} \\
\hline & & $\begin{array}{l}\text { Best } \\
\text { loc. }\end{array}$ & $\begin{array}{l}\text { Best } \\
\text { set. }\end{array}$ & $\begin{array}{l}\text { Best } \\
\text { loc. }\end{array}$ & $\begin{array}{l}\text { Best } \\
\text { set. }\end{array}$ & $\begin{array}{l}\mathrm{Pg} 1 \\
(\mathrm{pu})\end{array}$ & $\begin{array}{l}\mathrm{Pg} 2 \\
(\mathrm{pu})\end{array}$ & $\begin{array}{l}\mathrm{Pg} 3 \\
\text { (pu) }\end{array}$ & $\begin{array}{l}\text { Pg6 } \\
\text { (pu) }\end{array}$ & $\begin{array}{l}\mathrm{Pg} 8 \\
(\mathrm{pu})\end{array}$ & $\mathrm{T} 1$ & $\mathrm{~T} 2$ & $\mathrm{~T} 3$ & & & \\
\hline \multirow{2}{*}{ 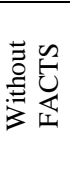 } & $\begin{array}{l}\text { Best } \\
\text { cost }\end{array}$ & - & - & - & - & 2.13 & 0.20 & 0.15 & 0.10 & 0.10 & 1.01 & 0.90 & 0.99 & 826.58 & 0.0703 & 0.71 \\
\hline & $\begin{array}{c}\text { Best } \\
\text { L. } \\
\text { Index }\end{array}$ & - & - & - & - & 0.93 & 0.80 & 0.50 & 0.10 & 0.30 & 0.90 & 0.90 & 1.10 & 991.61 & 0.0684 & 0.86 \\
\hline 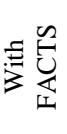 & $\begin{array}{c}\text { Best } \\
\text { KS } \\
\text { Solut } \\
\text { ion }\end{array}$ & $\begin{array}{c}\text { Bus } \\
9\end{array}$ & -0.73 & $\begin{array}{c}\text { Line } \\
4-9\end{array}$ & -0.80 & 2.14 & 0.20 & 0.16 & 0.10 & 0.10 & 1.09 & 0.97 & 1.10 & 829.10 & 0.0368 & 0.48 \\
\hline
\end{tabular}

\subsection{Lindex and Tloss}

The result of simulations is illustrated in Figure 8. Five non-dominated KS solutions are obtained, solution 2 is discarded as it is linked to the transformer. If we look at the voltage deviation index, the solution number (3) seems to be the best one. In this case, SVC is installed in bus 9 as well as the TCSC in the line bus 4-9. Both of them operate in capacitive state. The Table 3 shows the corresponding results in comparison with Lindex or Total losses DE optimization. From Table 3, it is clear that the best solution is given by KS solution, all objective functions were improved significantly which demonstrates the effectiveness of the approach in combination with Voltage Deviation Index and the contribution of FACTS in the power system.

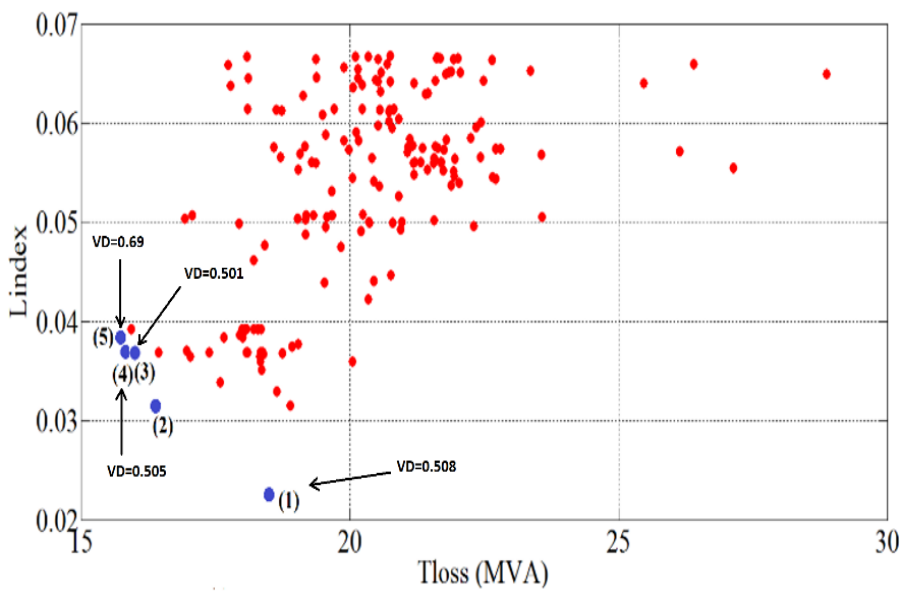

Figure 8. KS Solutions in case 5.3 
Table 3. Control variables and objective functions in case 5.3

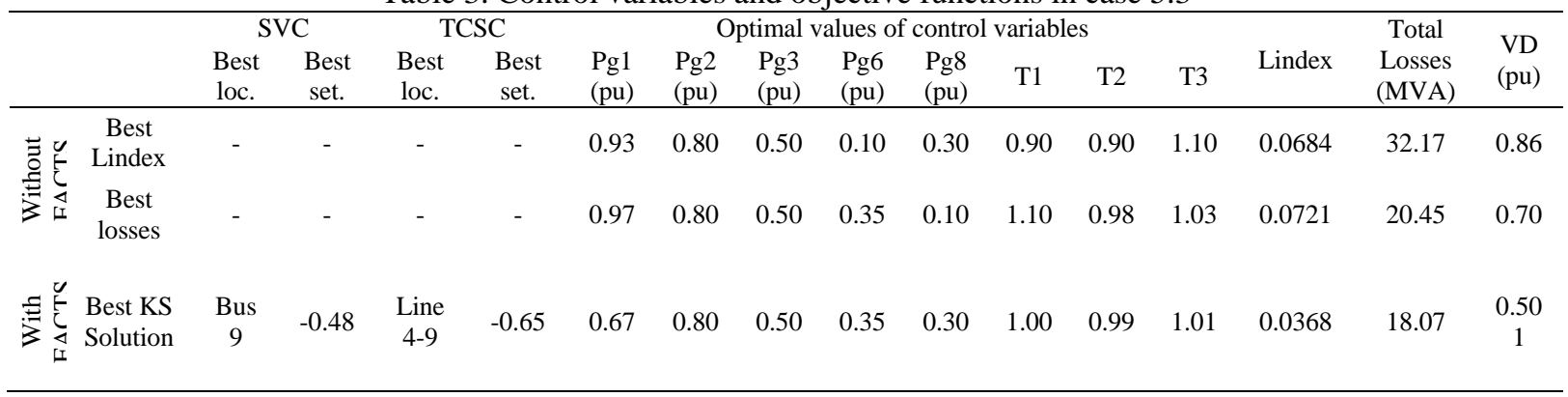

\section{CONCLUSION}

This paper presents an efficient, simple and fast approach for the SVC and TCSC optimal placement in the network; it was done on IEEE 14-bus test system by using KALAI Smorodinsky solution which gives a concrete solution. Several optimization techniques such as differential evolution and goal programming were used to achieve this target. Voltage Deviation Index was also used in case of many possible KS Solutions.

We were able to locate the best placement of SVC and TCSC in the power system which depends on the targets fixed by the operator, and secondly, the size of FACTS was computed. The approach used in this paper can be used for other objectives and other networks in order to improve their exploitations under optimal conditions.

\section{REFERENCES}

[1] S. P. Singh, "On-line Assessment of Voltage Stability using Synchrophasor Technology," Indonesian Journal of Electrical Engineering and Computer Science, vol/issue: 8(1), pp. 1-8, 2017.

[2] P. Kumar, "Enhancement of power quality by an application FACTS devices," International Journal of Power Electronics and Drive Systems (IJPEDS), vol/issue: 6(1), pp. 10-17, 2015.

[3] Z. Hamid, et al., "Stability index tracing for determining FACTS devices placement locations," Power Engineering and Optimization Conference (PEDCO) Melaka, Malaysia, 2012 IEEE International, pp. 17-22, 2012.

[4] E. B. Martinez and C. Á. Camacho, "Technical comparison of FACTS controllers in parallel connection," Journal of Applied Research and Technology, vol/issue: 15(1), pp. 36-44, 2017.

[5] S. Dutta, et al., "Optimal allocation of SVC and TCSC using quasi-oppositional chemical reaction optimization for solving multi-objective ORPD problem," Journal of Electrical Systems and Information Technology, 2016.

[6] K. V. R. Reddy, et al., "Improvement of Voltage Profile through the Optimal Placement of FACTS Using L-Index Method," International Journal of electrical and Computer engineering (IJECE), vol/issue: 4(2), pp. 207-211, 2014.

[7] A. Bagherinasab, et al., "Optimal placement of D-STATCOM using hybrid genetic and ant colony algorithm to losses reduction," International Journal of Applied Power Engineering (IJAPE), vol/issue: 2(2), pp. 53-60, 2013.

[8] N. A. Le, et al., "The Modeling of SVC for the Voltage Control in Power System," Indonesian Journal of Electrical Engineering and Computer Science, vol/issue: 6(3), pp. 513-519, 2017.

[9] N. R. H. Abdullah, et al., "Multi-Objective Evolutionary Programming for Static VAR Compensator (SVC) in Power System Considering Contingencies (Nm)," International Journal of Power Electronics and Drive Systems (IJPEDS), vol/issue: 9(2), pp. 880-888, 2018.

[10] A. Safari, et al., "Optimal setting and placement of FACTS devices using strength Pareto multi-objective evolutionary algorithm," Journal of Central South University, vol/issue: 24(4), pp. 829-839, 2017.

[11] K. M. Metweely, et al., "Multi-objective optimal power flow of power system with FACTS devices using PSO algorithm," Power Systems Conference (MEPCON), 2017 Nineteenth International Middle East. IEEE, pp. 12481257, 2017.

[12] A. Naganathan and V. Ranganathan, "Improving Voltage Stability of Power System by Optimal Location of FACTS Devices Using Bio-Inspired Algorithms," Circuits and Systems, vol/issue: 7(06), pp. 805, 2016.

[13] W. D. Rosehart, et al., "Multiobjective optimal power flows to evaluate voltage security costs in power networks," IEEE Transactions on power systems, vol/issue: 18(2), pp. 578-587, 2003.

[14] D. Radu and Y. Besanger, "A multi-objective genetic algorithm approach to optimal allocation of multi-type FACTS devices for power systems security," Power Engineering Society General Meeting, IEEE, pp. 8, 2006.

[15] S. Alamelu, et al., "Optimal siting and sizing of UPFC using evolutionary algorithms," International Journal of Electrical Power \& Energy Systems, vol. 69, pp. 222-231, 2015.

[16] S. Jeyadevi, et al., "Solving multiobjective optimal reactive power dispatch using modified NSGAII," International Journal of Electrical Power \& Energy Systems, vol/issue: 33(2), pp. 219-228, 2011.

[17] A. Yousefi, et al., "Optimal locations and sizes of static var compensators using NSGA II," Australian Journal of Electrical and Electronics Engineering, vol/issue: 10(3), pp. 321-330, 2013. 
[18] R. Benabid, et al., "Optimal location and setting of SVC and TCSC devices using non-dominated sorting particle swarm optimization," Electric Power Systems Research, vol/issue: 79(12), pp. 1668-1677, 2009.

[19] E. Kalai and M. Smorodinsky, "Other solutions to Nash's bargaining problem," Econometrica: Journal of the Econometric Society, pp. 513-518, 1975.

[20] R. Aboulaich, et al., "The Mean-CVaR Model for Portfolio Optimization Using a Multi-Objective Approach and the Kalai-Smorodinsky Solution," MATEC Web of Conferences. EDP Sciences, pp. 00010, 2017.

[21] T. Niknam, et al., "A modified shuffle frog leaping algorithm for multi-objective optimal power flow," Energy, vol/issue: 36(11), pp. 6420-6432, 2011.

[22] R. Storn and K. Price, "Differential evolution-a simple and efficient heuristic for global optimization over continuous spaces," Journal of global optimization, vol/issue: 11(4), pp. 341-359, 1997.

[23] A. M. Shaheen, et al., "A review of meta-heuristic algorithms for reactive power planning problem," Ain Shams Engineering Journal, 2015.

[24] https://www2.ee.washington.edu

[25] M. S. Kumar, et al., "Optimal Location and Rating of Thyristor Controlled Series Capacitor for Enhancement of Voltage Stability using Fast Voltage Stability Index (FVSI) Approach,” International Journal of Computer Applications, vol/issue: 46(10), 2012.

[26] P. Kessel and H. Glavitsch, "Estimating the voltage stability of a power system," IEEE Transactions on power delivery, vol/issue: 1(3), pp. 346-354, 1986.

[27] A. Oukennou and A. Sandali, "Assessment and analysis of Voltage Stability Indices in electrical network using PSAT Software," Power Systems Conference (MEPCON), 2016 Eighteenth International Middle East. IEEE, pp. 705-710, 2016. 